\title{
International exchange: Come on, young people! You should try going abroad!
}

\author{
Hiroshi E. Takami
}

Board of Directors and Chair of the Planning and Public Relations Committee, The Japan Endocrine Society

Professor and Chairman, Department of Surgery, Teikyo University School of Medicine, Tokyo 173-8605, Japan

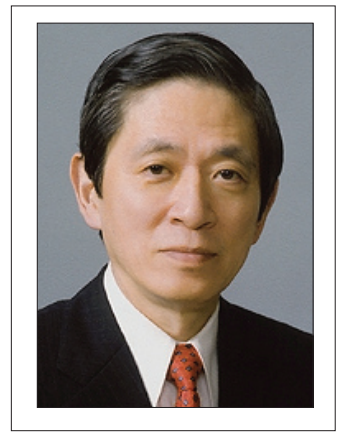

\section{To Endocrine Researchers}

The number of papers sent to international medical journals and participants in international conferences has by no means decreased in recent years. However, the number of young people who go abroad has. I do not necessarily have an accurate view of trends seen around the world, but, at least in Japan, the number of young people in the field of medicine and natural sciences who opt to go outside the country to try their luck is declining dramatically. Are they thinking that, even if they went abroad, they would gain very little as a scholar? Do they feel that their overseas experiences do not benefit them in their job hunting activities? Or, are they chickening out since they come from Japan, one of the countries with the lowest English conversation and writing skills in the world?

No matter what the field is, to become a leader, one must have a broad range of interpersonal connections. Globalization is expected to advance even further in the years ahead, so friends from different countries with whom you have studied together in a foreign country, would become a valuable asset to your subsequent life.

At present, Japan's social and governmental system is extremely weak when it comes to encouraging and supporting young people to go out into the world. It appears that government officials themselves who are planning this international exchange may have an "inward-looking" mentality. I urge the government to back up young energetic researchers filled with hopes and dreams who are willing to study at an overseas university even for a short period of time, or engage in
NGO activities in developing countries.

On the other hand, I feel sorry for those young researchers since they have to live amid this super icycold job market. On top of this, there is the issue of tuition. With national universities, students who take a leave of absence from their schools are exempt from paying tuition. In contrast, many private universities often demand that their students pay tuition even during such periods. Furthermore, there are numerous unresolved issues such as exchange of credits with overseas universities, and interchanges during a set period of time.

Still, I want to tell young researchers that they should not take an inward-looking mentality, but should go out of the country and cultivate a spirit of taking on challenges. It appears to me that, after the bursting of the bubble economy, both young people and their parents are placing the utmost importance on a stable life, and are avoiding the risks of living outside Japan.

After becoming upper-class students in college, students commit themselves $100 \%$ to job hunting activities. Medical school students are focused only on their goal to pass the national medical examination. Therefore, it is very difficult to foster a truly global human resource. Already, Japan's presence is weakening in international politics, economy, science and diplomacy. Under these circumstances, and if the nextgeneration human resources are not developed, I have a growing sense of alarm that Japan will definitely lose its influence and power as a nation.

Young people in many countries in the world are bravely challenging prestigious schools and universities in Europe and the US, which have turned out out- 
standing people. These people can not only receive high-quality education, but can also expand their network of interpersonal exchanges to transcend nationalities and races. Coming in contact with people who have a different history, culture, and customs becomes a major stimulation in their human development later on. Their experiences not only benefit their personal careers; from any nation's viewpoint, fostering global human resources would also become the foundation of that country's politics, economy, science and society, and determine the future of the country. This is common knowledge which prevails worldwide. 